\title{
Área e Perímetro nas pesquisas com alunos da Educação Básica: um estado do conhecimento
}

\author{
Area and Perimeter in research with Basic Education students: a state of knowledge
}

\author{
Maicon Quevedo Fontela ${ }^{1}$
}

Universidade Federal do Pampa

\author{
João Carlos Pereira de Moraes $^{2}$ \\ Universidade Federal do Pampa
}

\begin{abstract}
Resumo
Este estudo intenta analisar as práticas de pesquisa com alunos referente à área e perímetro na Educação Básica, quanto aos seus objetivos, metodologias de ensino e de pesquisa e suas inferências. Para tanto, analisamos três bases de dados: (a) Biblioteca Digital brasileira de Teses e Dissertações (BDTD); (2) Catálogo de Teses e Dissertações da Capes (CTD) e últimos dez anos do Encontro Nacional de Educação Matemática - ENEM. Perante essa investigação, evidenciamos que os estudos estão concentrados na região Sudeste do país; em sua maioria, são dissertações; e que não há elementos para suscitar um crescimento ou decrescimento das pesquisas nos últimos anos. Elencamos, ainda, a forte ênfase nas compreensões e manifestações dos alunos quanto aos conceitos de área e perímetro, bem como o foco em tarefas e atividades na configuração de metodologias de ensino e de pesquisa. Além disso, apontamos que muitos avanços são descritos de forma genérica, o que inviabiliza nossas considerações e produções na temática. Por fim, consideramos que este mapeamento pode contribuir para pesquisadores e docentes que ensejam adentrar na temática área e perímetro na Educação Básica, potencializando que diferentes formas de pensar tais conceitos possam vir à tona em pesquisas futuras.
\end{abstract}

Palavras-chave: Área; Perímetro; Estado do Conhecimento; Alunos da Educação Básica; Educação Matemática.

\begin{abstract}
This study intends to analyze the research practices with students regarding the area and perimeter in Basic Education, regarding their objectives, teaching and research methodologies and their inferences. For this, we analyzed three databases: (a) Brazilian Digital Library of Theses and Dissertations (BDTD); (2) Catalog of Theses and Dissertations by Capes (CTD) and last ten years of the National Meeting of Mathematical Education - ENEM. In view of this investigation, we show that the studies are concentrated in the Southeast region of the country; most of them are dissertations; and that there are no elements to encourage growth or decrease in research in recent years. We also list the strong emphasis on students' understandings and manifestations regarding the concepts of area and perimeter, as well as the focus on tasks and activities in the configuration of teaching and research methodologies. In addition, we point out that many advances are described in a generic way, which makes our considerations and productions on the subject unfeasible. Finally, we consider that this mapping can contribute to researchers and teachers who want to get into the thematic area and perimeter in Basic Education, enhancing that different ways of thinking about these concepts may come to the fore in future research.
\end{abstract}

Keywords: Area, Perimeter, State of Knowledge, Basic Education Students, Mathematics Education.

\footnotetext{
${ }^{1}$ Licenciado em Matemática (IFFar). Mestrando em Educação (UNIPAMPA), Jaguarão, Rio Grande do Sul, Brasil. Endereço para correspondência: Rua Conselheiro Diana, S/N, Jaguarão, Rio Grande do Sul, Brasil, CEP: 963000-000. $\quad$ ORCID $\quad$ iD: $\quad$ https://orcid.org/0000-0002-9146-7583. $\quad$ Lattes: http://attes.cnpq.br/6837138553537488. E-mail: fontelamaicon@gmail.com.

${ }^{2}$ Doutor em Educação (USP). Professor do Programa de Pós-Graduação em Educação (UNIPAMPA), Jaguarão, Rio Grande do Sul, Brasil. Endereço para correspondência: Rua Conselheiro Diana, S/N, Jaguarão, Rio Grande do Sul, Brasil, CEP: 963000-000. ORCID iD: https://orcid.org/0000-0001-9513-018X. Lattes: http://lattes.cnpq.br/5624816456388130. E-mail: joaomoraes@unipampa.edu.br.
} 


\section{Introdução}

Muitas vezes, é necessário acompanharmos os avanços e os anseios na área educacional, o que pode ser levantado a partir dos estudos de estado de conhecimento. Segundo Romanowski e Ens (2006), o estado do conhecimento direciona o observar e analisar de questões específicas em teses, dissertações e artigos em que abordam um determinado tema. No caso desse estudo, a temática envolvida consiste em área e perímetro.

No estado de conhecimento, estudamos as publicações dos trabalhos científicos em determinadas bases de dados, no propósito de realizar levantamentos das pesquisas e organizar as informações para que se possa fazer uma análise dos resultados, favorecendo na contribuição de novos estudos (FERNANDES; MORAES; PEREIRA, 2020).

Neste estudo, a intenção consiste em produzir um estado do conhecimento no campo da Educação Matemática, visando, mais especificamente, analisar as práticas de pesquisa com alunos referente à área e perímetro na Educação Básica, quanto aos seus objetivos, metodologias de ensino e de pesquisa e suas inferências.

\section{Aspectos metodológicos da composição do estado do conhecimento}

Para elucidar o leitor, no decorrer do estudo, descrevemos a metodologia de revisão, os resultados obtidos e, também, a forma que analisamos os trabalhos levantados. A metodologia de revisão será a partir da análise da natureza, região, objetivos, abordagens metodológicas e tipos de pesquisa encontrados nas bases de dados.

\section{Metodologia da revisão}

Elegemos inicialmente duas bases de dados: (a) Biblioteca Digital brasileira de Teses e Dissertações (BDTD) e (2) Catálogo de Teses e Dissertações da Capes (CTD), verificando a produção científica nos Programas de Pós-Graduação Stricto Sensu de Educação e Ensino, compreendido no periodo de 2010 a 2020, ou seja, nos últimos dez anos, com a finalidade de analisar teses e dissertações disponibilizadas em meio digital. 
Os descritores utilizados nessas bases foram "área e perímetro" AND "Educação Matemática”, o que remeteu 13 publicações na BDTD e 16 publicações no CTD, totalizando 29 publicações nas duas bases de dados, já excluindo as repetições. A partir do levantamento dos trabalhos e leitura do título e resumo, incluímos somente aqueles que possuem como sujeitos de pesquisa alunos da Educação Básica e, também, os que são na área da Educação Matemática. Perante tais filtros, resultaram 11 estudos.

Além disso, levantamos as pesquisas sobre área e perímetro também nos últimos dez anos do Encontro Nacional de Educação Matemática - ENEM (X ao XIII ENEM). Essa busca foi feita a partir do descritor "área e perímetro" e apenas nas comunicações orais, uma vez que acreditamos que nesse espaço ocorrem as descrições das pesquisas concluídas ou em andamento.

A partir dos descritores foram considerados os títulos e os resumos dos trabalhados, tanto nas plataformas de teses e dissertações quanto nos artigos levantados no ENEM. No intuito de analisar os contextos e suas inferências de área e perímetro desenvolvidos com os alunos nesses trabalhos, durante o período predeterminado.

\section{Resultado da pesquisa}

Ao longo dessa investigação, apresentamos os resultados encontrados a partir dos estudos realizados nas três bases de dados - BDTD, CDT e ENEM -, auxiliando na observância da natureza dos trabalhos, nas regiões em que foram desenvolvidos, ano de publicação, objetivos, abordagens metodológicas, tipos de pesquisas e suas conclusões. Todos esses aspectos serão identificados, elencados e discutidos, com o propósito de verificar suas relevâncias nesse estudo.

As publicações encontradas foram referentes ao conteúdo sobre área e perímetro na Educação Matemática, com o propósito de apontar os principais resultados encontrados e sistematizar os dados a fim de analisá-los. 
Quadro 1 - Título dos trabalhos pesquisados

\begin{tabular}{|c|c|c|c|c|}
\hline Termo* & Natureza & 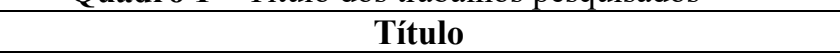 & Autor & Ano \\
\hline $\mathrm{T} 1$ & Dissertação & $\begin{array}{l}\text { Compreensão dos conceitos de área e perímetro: um } \\
\text { estudo de caso. }\end{array}$ & Quevedo & 2016 \\
\hline $\mathrm{T} 2$ & Dissertação & $\begin{array}{l}\text { Projeto de modelagem matemática e teoremas em ação: } \\
\text { uma investigação sobre os conceitos de área e perímetro. }\end{array}$ & Rosa & 2017 \\
\hline T3 & Dissertação & $\begin{array}{l}\text { Um estudo sobre a produção de significados de estudantes } \\
\text { do ensino fundamental para área e perímetro. }\end{array}$ & Henriques & 2012 \\
\hline T4 & Tese & $\begin{array}{l}\text { A prática da argumentação como método de ensino: o } \\
\text { caso dos conceitos de área e perímetro de figuras planas. }\end{array}$ & Nunes & 2011 \\
\hline T5 & Dissertação & $\begin{array}{c}\text { Uma análise das abordagens desenvolvidas em livros } \\
\text { didáticos sobre os conteúdos escolares "área" e } \\
\text { "perímetro". }\end{array}$ & Zils & 2018 \\
\hline T6 & Tese & $\begin{array}{c}\text { Um estudo sobre a transição do } 5^{\circ} \text { ano para o } 6^{\circ} \text { ano do } \\
\text { ensino fundamental: o caso da aprendizagem e do ensino } \\
\text { de área e perímetro. }\end{array}$ & Ferreira & 2018 \\
\hline $\mathrm{T} 7$ & Tese & Conceitos de área e de perímetro: um estudo metanalítico. & Senzaki & 2019 \\
\hline T8 & Dissertação & $\begin{array}{l}\text { Uma proposta para o ensino e aprendizagem dos conceitos } \\
\text { de área de círculo e perímetro de circunferência. }\end{array}$ & Paulo & 2012 \\
\hline T9 & Dissertação & $\begin{array}{l}\text { Uma análise praxeológica das tarefas referentes à } \\
\text { abordagem de área e perímetro nos anos finais do Ensino } \\
\text { Fundamental. }\end{array}$ & Canne & 2015 \\
\hline $\mathrm{T} 10$ & Dissertação & $\begin{array}{c}\text { Uma experiência pedagógica de uso de tecnologias no } \\
\text { ensino de área e perímetro com estudantes da Educação } \\
\text { de Jovens e Adultos (EJA) }\end{array}$ & Lasmar & 2016 \\
\hline T11 & Dissertação & $\begin{array}{c}\text { Práticas de ensino e aprendizagem de matemática e } \\
\text { tecnologia: um olhar para as especificidades da Educação } \\
\text { de Jovens e Adultos (EJA). }\end{array}$ & Borba & 2017 \\
\hline T12 & Artigo & $\begin{array}{c}\text { O tangram e suas contribuições para o processo de } \\
\text { abstração e compreensão dos conceitos geométricos de } \\
\text { área e perímetro. }\end{array}$ & Bezerra & 2016 \\
\hline T13 & Artigo & $\begin{array}{l}\text { Comparando área de figuras por visualização e } \\
\text { sobreposição. }\end{array}$ & Santos & 2013 \\
\hline T14 & Artigo & $\begin{array}{l}\text { Entre perímetros, áreas e equações: a conscientização das } \\
\text { ações de ensino. }\end{array}$ & Piovezan & 2013 \\
\hline $\mathrm{T} 15$ & Artigo & $\begin{array}{c}\text { As elaborações de estudantes do sexto ano do ensino } \\
\text { fundamental sobre o conceito de área a partir de } \\
\text { atividades orientadoras de ensino. }\end{array}$ & Prates & 2010 \\
\hline T16 & Artigo & $\begin{array}{l}\text { Aprendizagem dos conceitos de perímetro e área enquanto } \\
\text { grandezas na Educação de Jovens e Adultos (EJA): o } \\
\text { contexto desflorestamento da Amazônia. }\end{array}$ & Santos & 2010 \\
\hline T17 & Artigo & $\begin{array}{l}\text { A influência das variáveis didáticas na resolução de } \\
\text { problemas com área e perímetro. }\end{array}$ & Santos & 2010 \\
\hline $\mathrm{T} 18$ & Artigo & $\begin{array}{l}\text { Efeitos de uma sequência de atividades para a dissociação } \\
\text { entre área e perímetro no } 3^{\circ} \text { ciclo do Ensino Fundamental. }\end{array}$ & Pessoa & 2010 \\
\hline
\end{tabular}

*Observação: para otimizar a análise dos dados, cada trabalho recebeu a nomenclatura T e um número, conforme a ordem levantada.

Fonte: a pesquisa.

\section{$-4-$}

Revista de Investigação e Divulgação em Educação Matemática Juiz de Fora, v. 5, n. 1, p.1-22, Jan. - Dez., e-ISSN: 2594-4673, 2021 
Pode-se perceber um número significativo de trabalhos encontrados que abordam o conteúdo área e perímetro e também uma variedade na forma em que são desenvolvidos com os alunos. Tendo trabalhos no Ensino Fundamental e, até mesmo, na modalidade EJA.

\section{Análise dos dados}

A análise dos dados ocorreu em dois momentos: questões gerais e questões específicas. No primeiro momento, realizamos uma leitura geral dos estudos, pautando-se no ano de publicação, região do país de produção e natureza dos trabalhos.

No segundo momento, analisamos as pesquisas a partir de quatro perguntas norteadoras:

- $\quad$ Como se organiza o objetivo do trabalho?

- Quais as abordagens metodológicas utilizadas para o ensino de área e perímetro?

- Quais as metodologias de pesquisa utilizadas para a realização das investigações?

- Quais as principais inferências das pesquisas?

Para responder tais questionamentos, foram extraídos excertos dos trabalhos, os quais serviram de base para responder os questionamentos da revisão. Abaixo, apresentamos tais momentos de forma descritiva.

\section{Resultados e Discussões}

Para analisarmos os trabalhos, dispusemos no decorrer desta seção a distribuição em dois momentos. No primeiro momento observamos os aspectos gerais dos estudos, referente à região, natureza e ano de publicação. Já no segundo momento, ponderamos os objetivos gerais, as abordagens metodológicas, os tipos de metodologias e as conclusões das publicações. 


\section{Aspectos gerais}

Para facilitar a compreensão e debate, nessa seção, distribuímos os dados encontrados em tabelas. Cada item descreve a análise conforme apresentado nos estudos da pesquisa. Quanto à região, vemos a tabela abaixo:

\begin{tabular}{|c|c|c|}
\multicolumn{2}{|c|}{ Qradro 2: Distribuição das Regiões dos trabalhos. } \\
\begin{tabular}{|c|c|c|}
\hline Região & Quantidade & Trabalhos \\
\hline Sul & 3 & T1, T2 e T5. \\
\hline Sudeste & 9 & T3, T4, T7, T8, T9, T10, T11, T14 e T15. \\
\hline Norte & --------- \\
\hline Nordeste & 4 & T6, T16, T17 e T18. \\
\hline Centro-Oeste & 2 & T12 e T13. \\
\hline
\end{tabular}
\end{tabular}

Fonte: a pesquisa.

Como observamos acima, há maior número de trabalhos na região Sudeste, bem como nenhum trabalho na região Norte. Consideramos que um dos motivos de ter mais trabalhos na região sudeste associa-se pela concentração de cursos de pós-graduação nível stricto sensu em educação e ensino, bem como de pesquisadores destas áreas (FERNANDES, MORAES, PEREIRA, 2020). Já na região Norte há uma carência de trabalhos, visto que não encontramos nenhuma publicação.

Quanto à quantidade de teses, dissertações e artigos, elencamos a seguinte divisão:

Quadro 3: Natureza dos trabalhos.

\begin{tabular}{|c|c|c|}
\hline Natureza & Quantidade & Trabalhos \\
\hline Dissertação & 8 & $\mathrm{~T} 1, \mathrm{~T} 2, \mathrm{~T} 3, \mathrm{~T} 5, \mathrm{~T} 8, \mathrm{~T} 9, \mathrm{~T} 10, \mathrm{~T} 11$. \\
\hline Tese & 3 & $\mathrm{~T} 4, \mathrm{~T} 6, \mathrm{~T} 7$. \\
\hline Artigo & 7 & $\mathrm{~T} 12, \mathrm{~T} 13, \mathrm{~T} 14, \mathrm{~T} 15, \mathrm{~T} 16, \mathrm{~T} 17, \mathrm{~T} 18$. \\
\hline
\end{tabular}

Fonte: a pesquisa

A partir da separação, notamos que o número de dissertações (8) supera de modo significativo os trabalhos de tese. Entre os elementos que consideramos possíveis causas deste fato, apontamos a aproximação do mestrado com o processo reflexivo sobre a Educação Básica, uma vez que muitos docentes deste nível ingressam na Pós-Graduação com o desejo de refletir sobre sua prática, bem como a existência e crescimento de mestrados profissionais que 
vinculam a intervenção de pesquisa e o cotidiano de trabalho de seus estudantes. Por outro lado, verifica-se, ainda, a necessidade de trabalhos mais aprofundados em nível de tese sobre o tema.

Quanto ao ano de publicação, vemos a tabela abaixo.

Quadro 3: Ano de publicação dos trabalhos

\begin{tabular}{|c|c|c|}
\hline Ano & Quantidade & Trabalhos \\
\hline 2010 & 4 & T15, T16, T17 e T18. \\
\hline 2011 & 1 & T4. \\
\hline 2012 & 2 & T3 e T8. \\
\hline 2013 & 2 & T13 e T14 \\
\hline 2014 & --- & --- \\
\hline 2015 & 1 & T9. \\
\hline 2016 & 3 & T1, T10 e T12. \\
\hline 2017 & 2 & T2 e T11. \\
\hline 2018 & 2 & T5 e T6. \\
\hline 2019 & 1 & T7 \\
\hline 2020 & --- & --- \\
\hline
\end{tabular}

Fonte: a pesquisa.

Ao observarmos a divisão acima, encontramos mais trabalhos no ano de 2010 e nenhum trabalho nos anos de 2014 e $2020^{3}$. Mesmo assim, não é possível elencar processos de crescimento ou decrescimento do assunto, porque a quantidade de trabalhos por ano apresentase de modo esporádico.

Os dados coletados nessa seção indicam que apesar de existir um número significativo de trabalhos encontrados, ainda tem regiões brasileiras com poucas pesquisas que se atentam para a discussão sobre área e perímetro na Educação Matemática. Levantamos, ainda, que a natureza dos trabalhos necessita de maior diversificação, principalmente no aprofundamento em teses.

\section{Categoria 1: objetivos gerais dos trabalhos}

Nessa seção, faremos uma análise de todos os objetivos de pesquisa dos trabalhos encontrados de acordo com suas características. Apresentamos, ainda, uma divisão dos mesmos

\footnotetext{
${ }^{3}$ Vale ressaltar que a pesquisa foi realizada em dezembro de 2021. Nesse sentido, devemos considerar que muitas das dissertações e teses ainda não tiveram suas divulgações no BDTD e CDT.
} 
em grupos, com o intuito de agrupar e acompanhar o que cada trabalho se propôs em realizar no decorrer de cada pesquisa. A partir disso, obtivemos os seguintes grupos:

\begin{tabular}{|c|c|c|}
\hline \multicolumn{3}{|c|}{ Quadro 4: Objetivos gerais } \\
\hline Focos dos objetivos & Quantidade & Trabalhos \\
\hline $\begin{array}{c}\text { Diagnósticos de manifestações e Compreensão } \\
\text { do conceito }\end{array}$ & 8 & $\begin{array}{c}\mathrm{T} 1, \mathrm{~T} 2, \mathrm{~T} 3, \mathrm{~T} 4, \mathrm{~T} 6, \mathrm{~T} 10, \mathrm{~T} 15 \mathrm{e} \\
\text { T17 }\end{array}$ \\
\hline $\begin{array}{l}\text { Acompanhar, produzir e analisar processos de } \\
\text { aprendizagem do conceito }\end{array}$ & 5 & T16, T18, T13, T11 e T12 \\
\hline $\begin{array}{l}\text { Acompanhar, produzir e analisar processos de } \\
\text { ensino do conceito }\end{array}$ & 2 & $\mathrm{~T} 14$ e T8 \\
\hline Perceber o conceito em materiais & 3 & T5, T9 e T7 \\
\hline
\end{tabular}

Fonte: a pesquisa

No primeiro grupo, denominado Diagnósticos de manifestações e compreensão do conceito, buscamos agrupar os estudos que visam identificar o pensamento de estudantes sobre área e perímetro.

No interior deste grupo, podemos ver objetivos relativos à compreensão:

Identificar e analisar como os estudantes compreendem os conceitos de área e perímetro (T1).

Analisar em que medida a prática da argumentação pode se apresentar como método que favoreça a compreensão de conceitos em matemática, tomando como referência o caso da área e perímetro de figuras planas (T4).

Em T1, trabalhou-se com uma turma do nono ano do ensino fundamental, durante nove horas-aula, uma sequência de atividades. Nas atividades foram propostos problemas que discutiam o tema, os estudantes eram convidados a medir, visualizar construções geométricas, aplicar os conceitos e executarem cálculos. Sendo possível fazer uma análise de como os estudantes compreendiam os conceitos sobre área e perímetro.

Já no T4, utilizou-se a prática da argumentação, por meio de uma sequência didática modelada e analisada com base nas fases que compõem o processo argumentativo. Analisando como o método pode auxiliar na compreensão dos conceitos propostos.

Outro subgrupo que pode ser visto também neste grupo, discutem o que os alunos pensam sobre o conceito de área e perímetro: 
projeto de Modelagem Matemática, a respeito dos conceitos de área e de perímetro (T2).

Analisar de que modos às tecnologias podem ser usadas para se criar um ambiente em que estudantes da EJA possam produzir significados para as ideias de área e perímetro (T10).

Analisar as elaborações dos estudantes do sexto ano do ensino fundamental diante de atividades orientadoras de ensino relacionadas à alguns aspectos da grandeza área (T15) (Grifos nossos).

No T2, procurou-se trabalhar questões contextualizadas na intenção de identificar o que os alunos sabiam sobre área e perímetro, a partir de teoremas em ação falsos. Também foi aplicado o projeto de modelagem matemática, outra maneira de identificar o saber matemático sobre o conteúdo trabalhado de acordo com os teoremas.

Já T10 buscou planejar, realizar e analisar atividades de geometria, abordando os conteúdos, área e perímetro, com o uso de tecnologias. Explorando o uso de tecnologias da informação e comunicação, como vídeos, filmagens, fotografias, computador, internet e/ou programas de computador e, também, réguas, trenas, fita métrica, compassos, transferidores e calculadoras para abordar o assunto.

No T15, a pesquisa foi analisada a partir das elaborações que os estudantes do sexto ano do Ensino Fundamental fizeram enquanto vivenciaram algumas situações-problema que envolveu o conceito de área.

Ainda nesse grupo, elaboramos outro subgrupo relativo ao desempenho dos alunos sobre o conceito área e perímetro:

Levantar possíveis dificuldades de aprendizagem das noções de área e perímetro de figuras geométricas planas (T3).

Investigar fatores de natureza epistemológica, cognitiva, didática e pedagógica relativos à transição entre a primeira e a segunda etapa do ensino fundamental e aos objetos de saber área e perímetro e sua possível influência sobre o modo como os alunos do $6^{\circ}$ ano lidam com esses objetos (T6).

Diagnosticar o desempenho dos alunos do $9^{\circ}$ ano de uma escola pública da zona da mata pernambucana, com respeito aos conhecimentos referentes às grandezas geométricas: área e perímetro (T17) (grifos nossos). 
No T3, utilizou-se à elaboração de um conjunto de tarefas que possibilitasse identificar a produção de significados de estudantes do ensino fundamental para área e perímetro, e também levantar possíveis dificuldades encontradas na realização das tarefas.

Em sentido semelhante, T6 buscou investigar quais as dificuldades conceituais enfrentadas pelos alunos ao resolver situações relativas à área e ao perímetro na transição entre o $5^{\circ}$ e o $6^{\circ}$ anos do ensino fundamental, bem como suscitar os elementos que ajudam a compreender as possíveis dificuldades encontradas nessa etapa de transição.

No T17, realizou-se um estudo diagnóstico, em que foram analisados os conhecimentos dos alunos sobre área e perímetro a partir das atividades desenvolvidas na turma do $9^{\circ}$ ano.

Nesse sentido, vemos que neste grupo o foco caminha na compreensão, pensamento e desempenho. Com isso, as pesquisas suscitam o que os alunos manifestam sobre área e perímetro em suas ações falas.

No segundo grupo, refere-se a acompanhar, produzir e analisar processos de aprendizagem do conceito. Nesse grupo, encontramos dois subgrupos. Um deles, ligados à sequência didática:

Analisar uma sequência de atividades composta por três questões envolvendo as grandezas, área e perímetro, elaboradas a partir do contexto Meio Ambiente (T16).

Propor uma sequência de atividades que favorecem a compreensão da dissociação entre área e perímetro, numa turma de alunos do Ciclo III $/ 2^{\circ}$ ano do Ensino Fundamental ( $\left.7^{\circ} \mathrm{Ano}\right)$, de uma escola da rede pública municipal do Recife (T18).

Apresentar e analisar uma atividade da sequência didática na qual comparou-se áreas por visualização e sobreposição (T13) (grifos nossos).

No T16, as atividades foram aplicadas com vinte alunos do $8^{\circ}$ e $9^{\circ}$ ano (Módulo II) da Educação de Jovens e Adultos (EJA), de uma escola municipal do Recife-Pernambuco (PE). Cada questão contemplava a situação de comparação, medição e produção, envolvendo o contexto do desflorestamento da Amazônia.

No T18, aborda intuitivamente a noção de área e perímetro, comparando (com e sem medidas) e medindo essas grandezas. $\mathrm{O}$ intuito consistia em favorecer a compreensão entre o que é área e o que é perímetro, por meio de uma sequências de atividades. 
T13, por sua vez, apresenta questões epistemológicas e metodológicas vinculadas à apropriação da História da Matemática utilizada como recurso didático para a comparação de áreas por visualização.

O outro subgrupo refere-se às metodologias:

Investigar as potencialidades da tecnologia educacional no processo de ensino e aprendizagem de Matemática no âmbito da EJA (T11).

Analisar as experiências vivenciadas durante a atuação em uma turma do $6^{\circ}$ ano do Ensino Fundamental, trabalhando com conteúdo de Geometria Plana associado a materiais manipuláveis (T12) (grifos nossos).

T11 tem como foco estudar, investigar, observar e evidenciar as possíveis contribuições para o processo de aprendizagem de tarefas exploratórias investigativas de matemática permeadas pelas TICs, no âmbito da Educação de Jovens e Adultos.

Em seguida, T12, utilizou-se o material manipulável, apresentando como um elemento facilitador no desenvolvimento dos conceitos e atividades, possibilitando ao aluno uma melhor visualização do conteúdo de geometria e das propriedades e conceitos trabalhados em sala de aula.

Nesse sentido, o grupo como um todo se preocupa com o elaborar a prática pedagógica para favorecer e potencializar a aprendizagem. Vale ressaltar, a ênfase dada para sequências didáticas, uma vez que elas permitem ao pesquisador uma melhor organização do fazer docente e, consequentemente, do processo de sua pesquisa (PERETTI; COSTA, 2013).

No terceiro grupo, refere-se a acompanhar, produzir e analisar processos de ensino do conceito. Nesse grupo, encontramos dois objetivos principais:

Analisar as ações de uma professora na interação com os estudantes orientada pelo planejamento que contemplava princípios e conceitos da teoria histórico-cultural como significado, mediação, instrumentos psicológicos, etc. (T14).

Estudar os processos de ensino e aprendizagem dos conceitos de área de círculo e perímetro de circunferência no Ensino Fundamental II (T8).

No primeiro deles, T14, foram feitas as análises das ações durante um semestre, em que uma professora e uma estudante de doutorado realizaram um planejamento conjunto 
direcionado aos estudantes de uma turma de $7^{\circ}$ ano do Ensino Fundamental de uma escola da rede municipal de São Paulo.

Por sua vez, T8 debateu os processos de ensino e aprendizagem dos conceitos de área de círculo e perímetro de circunferência, através de uma sequência didática. O público-alvo do estudo compôs-se de alunos de $9^{\circ}$ ano do Ensino Fundamental.

Neste grupo, embora a presença de alunos como sujeitos de pesquisa seja levantada, os debates desenvolvidos tencionam os processos de ensino dos conceitos de área e perímetro, buscando potencialidades para a atuação docente a partir da interação e práticas com os alunos.

No quarto grupo, refere-se a perceber o conceito em materiais. Nesse grupo, encontramos três trabalhos:

\begin{abstract}
Analisar e discutir como os conteúdos escolares Área e Perímetro são abordados pelos livros didáticos de matemática distribuídos pelo PNLD (T5).

Investigar como são institucionalizadas as noções de área e perímetro nos anos finais do Ensino Fundamental nos Cadernos de Matemática do Aluno e do Professor do Ensino Fundamental do Estado de São Paulo, elaborados pela Secretaria Estadual de Educação, conforme o Currículo vigente (T9).

Explicar os diferentes aspectos das pesquisas selecionadas, com vistas a analisar as questões investigadas, assim como, as convergências e divergências em relação às dificuldades relacionadas ao ensino e aprendizagem de conceitos de área e perímetro de figuras planas (T7).
\end{abstract}

No T5, a investigação foi analisar e discutir a importância do livro didático nos processos educacionais, visto que o seu uso em sala de aula é fomentado por políticas públicas de Estado, através do Programa Nacional do Livro Didático (PNLD).

T9, por sua vez, buscou investigar como são institucionalizadas as noções de área e perímetro e o que revelam os cadernos de matemática do aluno e professor referente aos conteúdos.

Por fim, T7 procurou analisar e explicar as convergências e/ou divergências que revelam pesquisas acadêmicas brasileiras desenvolvidas entre 1996 e 2017, sobre os processos de ensino e aprendizagem dos objetos matemáticos área e perímetro.

As pesquisas deste último grupo, mesmo apresentando intervenções com sujeitos alunos da Educação Básica, ponderam essa relação com materiais diversos que permeiam o cotidiano do alunado. 


\section{Categoria 2: abordagens metodológicas usadas para o ensino área e perímetro}

Nessa seção, temos como objetivo apontar as principais abordagens metodológicas de ensino utilizadas nos estudos desenvolvidos. As abordagens que foram encontradas são apresentadas na Tabela 5.

\begin{tabular}{|c|c|c|}
\hline Ahordagem & Onontidod & Trobolboc \\
\hline Atividades e tarefas & 8 & T1 T3 T6 T8 T14 T15 T17 T18 \\
\hline Tecnologia & 2 & $\mathrm{~T} 10, \mathrm{~T} 11$ \\
\hline Análise de material & 3 & T9, T5, T7 \\
\hline Prática da argumentação & 1 & T4 \\
\hline Materiais manipuláveis & 1 & T12 \\
\hline História da Matemática & 1 & T13 \\
\hline Modelagem matemática & 2 & $\mathrm{~T} 2, \mathrm{~T} 16$ \\
\hline
\end{tabular}

Fonte: a pesquisa

No grupo 1, atividades e tarefas, encontramos oito trabalhos que foram desenvolvidos com a utilização de sequências de atividades para contribuir na compreensão de área e perímetro.

No T1, a partir dos problemas que discutiam o tema, foram feitas discussões sobre o porquê dos alunos apresentarem dificuldades e/ou êxitos nos problemas. Podendo analisar as resoluções de cada aluno, por meio das atividades aplicadas na sala de aula. Já, no T3, o propósito foi confeccionar um produto educacional que consiste de uma série de tarefas, a serem utilizadas por professores que lecionam para classes do quarto ciclo do Ensino Fundamental, bem como orientações didáticas que possam auxiliar o trabalho docente de aplicar tais tarefas, em sala de aula.

No T6, a pesquisa foi desenvolvida na cidade do Recife e teve como participantes alunos que cursaram o $5^{\circ}$ ano (2016), o $6^{\circ}$ ano (2017) e o $7^{\circ}$ ano (2018); diretoras, coordenadoras dos anos iniciais e dos anos finais; e professores de matemática das turmas de $5^{\circ}$ ano (2016) e $6^{\circ}$ ano (2017). Para responder às questões, três estudos foram elaborados. T8, por sua vez, realizou uma sequência didática, com atividades que permitia ao aluno à comparação de área do círculo e perímetro da circunferência com a área e perímetro de outras figuras, assim minimizaria as dificuldades na compreensão e diferenciação desses dois objetos matemáticos. 
No T14, apresentou-se a organização e a análise das ações da professora, na interação com os estudantes, orientada pelo planejamento de atividades com a temática de área e perímetro. Já no T15, a realização e a coleta dos dados ocorreram em uma escola pública estadual do interior do estado de São Paulo, diante de atividades orientadoras de ensino relacionadas a alguns aspectos da grandeza área, envolvendo estudantes do sexto ano do ensino fundamental.

No T17, foi desenvolvido um estudo diagnóstico para analisar as mudanças na didática a partir do estudo sobre área e perímetro. E, ainda, no T18, propôs-se uma sequência de atividades que favorecem a compreensão da dissociação entre área e perímetro, numa turma de alunos do ciclo III do ensino fundamental ( $7^{\circ}$ Ano).

Neste grupo, percebemos a preocupação no campo da Educação Matemática com a elaboração consciente e sequencial de tarefas matemáticas na Educação Básica. Nesse sentido, ressaltamos o papel do planejamento como estrutura organizacional da atuação docente, o conhecimento de currículo como forma de compreender o processo de produção dos objetos matemáticos e, ainda, as práticas avaliativas diagnósticas e processuais como maneira de compreender os momentos em que os alunos se localizam.

No grupo 2, referente a tecnologia, temos dois estudos. O primeiro, T10, constitui-se de uma pesquisa elaborada com uma sequência didática atrelada com o uso das tecnologias como ferramenta no processo de ensino-aprendizagem. Constituiu-se por meio dos dados coletados, nas observações de aulas, em discussões e pelas atividades, realizadas pelos estudantes. No segundo, T11, delinearam-se duas propostas de ensino, uma abordando os conteúdos de área e perímetro, que utilizou como recurso pedagógico somente as TICs, e a outra proposta de ensino abarcou os conteúdos de simetria e ângulo, conciliando as TICs e o espelho plano.

Embora este grupo traga o elemento das tarefas e atividades, seu foco aponta para a questão das tecnologias. Os estudos fundamentam-se na potencialidade deste recurso e possibilidade metodológica para intervir no pensamento matemático dos alunos, ou seja, como aponta Oliveira (2020), como um espaço de reflexão, manipulação, criação de hipóteses e, consequentemente, de produção de conhecimento. 
No grupo 3, análise de material, elencamos três estudos (T9, T5, T7). No T9, vemos o uso de cadernos de matemática do aluno e do professor. T5, a pesquisa partiu de livros didáticos. Por fim, T7 enfatizou pesquisas evidenciou pesquisas da área. Neste grupo, os materiais tornaram-se subsidio para práticas com os sujeitos de pesquisa.

Por sua vez, no grupo 4, prática da argumentação, temos o T4, em que utilizou o processo argumentativo como premissa para relação pesquisador-sujeito. A ênfase desse estudo configura-se no processo de diálogo em contexto de sala de aula, oferecendo a este um status de proposta teórico-metodológica.

Já no grupo 5, materiais manipuláveis, T12 desenvolve a utilização do Tangram como material manipulável para o ensino de área e perímetro. A conotação dada ao Tangram fixa-o como recurso facilitador no decorrer do desenvolvimento dos conceitos e atividades de matemática, possibilitando ao aluno a criação de relações difíceis de realizar de outro modo.

No grupo 6, história da matemática, visualizamos o debate do T13. Esse estudo apresenta questões vinculadas à apropriação da história da matemática, por meio de uma sequência didática, para utilização como recurso didático para o ensino e aprendizagem de conceitos matemáticos.

Por fim, no grupo 7, modelagem matemática, encontramos dois estudos (T2, T16). T2, após diagnóstico, elabora questões contextualizadas, relacionando com a metodologia de modelagem matemática. T16, ainda, utilizou-se de uma proposta de modelagem matemática, envolvendo as grandezas, área e perímetro na EJA.

Ao todo, sobre os tipos de abordagens utilizadas, destaca-se uma preferência por se desenvolver ferramentas para o processo de ensino-aprendizagem por meio de atividades e tarefas. Ressaltamos que, mesmo aquelas propostas que não participam do grupo citado, vinculam sua atuação de maneira secundária a ações sequenciais de ensino de tarefas e atividades. A proposta de se utilizar materiais manipuláveis, prática de argumentação, história da matemática, modelagem matemática, análise de material e o uso das tecnologias também devem ser destacados no processo de ensino-aprendizagem de área e perímetro, visto que todas essas abordagens somam como possibilidade metodológica que favorecem na problematização dos alunos na compreensão dos conceitos. 


\section{Categoria 3: metodologias de pesquisa utilizadas nos trabalhos}

Nessa seção, levantaremos as metodologias de pesquisa utilizadas em cada trabalho. Dessa forma, para facilitar a análise, organizamos os trabalhos em uma tabela, de acordo com o tipo de metodologia.

\begin{tabular}{|c|c|c|}
\multicolumn{4}{|c|}{ Quadro 6: Metodologias utilizadas } \\
\hline Metodologia de pesquisa & Quantidade & Trabalhos \\
\hline Pesquisa-ação & 1 & $\mathrm{~T} 11$, \\
\hline Estudo de caso & 5 & $\mathrm{~T} 1, \mathrm{~T} 2, \mathrm{~T} 3, \mathrm{~T} 6, \mathrm{~T} 10$ \\
\hline Documental e Metanálise & 3 & $\mathrm{~T} 5, \mathrm{~T} 7, \mathrm{~T} 9$ \\
\hline Engenharia Didática & 3 & $\mathrm{~T} 4, \mathrm{~T} 8, \mathrm{~T} 13$ \\
\hline Sem denominação explícita & 6 & $\mathrm{~T} 12, \mathrm{~T} 14, \mathrm{~T} 15, \mathrm{~T} 16, \mathrm{~T} 17, \mathrm{~T} 18$ \\
\hline
\end{tabular}

Fonte: a pesquisa

No grupo 1, pesquisa-ação, encontramos apenas T11. A pesquisa promoveu os procedimentos de observar os benefícios e as dificuldades do uso da tecnologia na EJA, realização de uma intervenção a partir do levantado e avaliação dos benefícios no processo de aprendizagem de Matemática perante o grupo. Nesse contexto, T11 corrobora o pensamento de Tripp (2005, p. 443), em que ressalta a "pesquisa-ação como uma das muitas diferentes formas de investigação-ação, a qual é por ele sucintamente definida como toda tentativa continuada, sistemática e empiricamente fundamentada de aprimorar a prática” (TRIPP, 2005, p. 443).

Já no grupo 2, estudo de caso, emergiram 5 estudos (T1, T2, T3, T6, T10). Segundo Lüdke e André (1986), um estudo de caso surge pelo seu potencial delimitado de um segmento da realidade, representando valor enquanto unidade contextualizada dessa. Ou seja, gera-se um 'único' coeso e atrelado a um contexto maior para ser espaço da pesquisa. Quanto às pesquisas que abordam o estudo de caso, visualizamos que todas se apoiam na sala de aula como esse espaço de unicidade, considerando-a como representativo da realidade educacional.

No grupo 3, documental e metanálise, surgiram três estudos (T5, T7, T9). Os estudos percebem os materiais pedagógicos como objetos para a investigação, o que permitiu análises bibliográficas (T5), estruturação de fonte dados (T9) e uma análise reflexiva pelos processos de construção das próprias pesquisas (T7). O pressuposto deste grupo envolve evidenciar e problematizar a Educação Matemática envolta no tema área e perímetro. 
Três estudos também foram encontrados no grupo 4 (T4, T8, T13), engenharia didática. Segundo Almouloud e Coutinho (2009), a engenharia didática, como metodologia de pesquisa, "caracteriza-se, em primeiro lugar, por um esquema experimental baseado em "realizações didáticas" em sala de aula, isto é, na concepção, realização, observação e análise de sessões de ensino" (p. 66), Nesse sentido, os três estudos apropriam-se da didática da matemática para pensar e realizar experimentos em sala de aula sobre o conceito de área e perímetro.

Por fim, no grupo 5, sem denominação explícita, junta-se uma lista de produções que realizam atividades e tarefas sem associa-las a nenhuma metodologia específica (T12, T14, T15, T16, T17, T18). Embora detalhadas, consideramos essa abordagem arriscada como metodologia de pesquisa, uma vez que a associação com elaborações teórico-metodológicas oportunizariam para os estudos características de credibilidade, rigor e sistematização mais evidentes.

\section{Categoria 4: principais inferências dos estudos}

Nessa categoria, descrevemos as principais inferências presentes no resumo de cada trabalho, na intenção de apresentar como os resultados foram significados ao final das aplicações das pesquisas. As inferências foram divididas em dois grupos: avanços genéricos e avanços específicos.

\begin{tabular}{|c|c|c|}
\hline \multicolumn{3}{|c|}{ Quadro 7: Principais Inferências } \\
\hline Inferências & Quantidade & Trabalhos \\
\hline Avanços Genéricos & 11 & T3, T7, T8, T15, T14, T9, T10, \\
& $711, \mathrm{~T} 12, \mathrm{~T} 4 \mathrm{e} \mathrm{T5}$. \\
\hline Avanços específicos & 7 & $\mathrm{~T} 1, \mathrm{~T} 2, \mathrm{~T} 6, \mathrm{~T} 13, \mathrm{~T} 16, \mathrm{~T} 17 \mathrm{e}$ \\
& & T18. \\
\hline
\end{tabular}

Fonte: a pesquisa

No grupo de avanços genéricos não visualizamos explicações mais detalhadas dos resultados obtidos na pesquisa. Em nossa análise, dividimo-lo em dois subgrupos: significados conceituais e instrumentos de melhoria de aprendizagem.

No primeiro subgrupo significados conceituais, percebemos expressões: "produção de significados" (T3), "geraram aproximações e percepções” (T7), "avanço na compreensão do 
significado" (T8) e "nexos conceituais do conceito de área e perímetro" (T15). Neste subgrupo, percebemos discussões gerais quanto ao aprendizado dos alunos frente ao conceito, descrevendo que as intervenções de pesquisa trouxeram benefícios ao grupo.

O segundo subgrupo refere-se a instrumentos de melhoria de aprendizagem, em que são ressaltados os termos: "interação entre estudantes" (T14), "tarefas tem o potencial de influenciar na aprendizagem dos conteúdos abordados" (T9), "favorecimento de uma aprendizagem significativa" (T10), "contribuição do uso das tecnologias" (T11), "potencialização da abstração da abstração dos conteúdos e do reconhecimento das distintas representações inerentes a eles" (T12), "prática da argumentação" (T4) e "não pode ser considerado o único material de apoio" (T5). Assim, no subgrupo em questão, os resultados inserem-se na perspectiva de valorização dos elementos (recursos e/ou metodologias) no processo de aprendizagem dos alunos.

No segundo grupo, avanços específicos, há explicações mais detalhadas dos resultados. Podemos ver as seguintes considerações:

Verificamos que muitos dos erros cometidos pelos estudantes estavam ligados a um mau entendimento dos conceitos envolvidos nos problemas, e que a maioria, durante a resolução das atividades, tentava aplicar as definições e fórmulas mesmo em situações que não fazia sentido aplicá-las (T1).

Os resultados obtidos indicaram que, nas questões contextualizadas e propostas para serem resolvidas no papel, os alunos também apresentaram teoremas em ação falsos, conforme apontados na literatura, no entanto, durante a realização do projeto de Modelagem Matemática, envolvendo o problema da pintura do muro da escola, não identificamos, nas ações dos alunos, a manifestação desses teoremas (T2).

Esse estudo mostrou que as praxeologias ensinadas pelos professores se aproximam daquelas dos livros adotados e os tipos de tarefas predominantes são medir uma área e medir um perímetro (T6).

Propiciou a percepção dos conhecimentos prévios do aluno, além de demonstrar a apropriação, por algumas crianças, de procedimentos que apontam a relação existente na história entre o processo de composição e decomposição e a determinação da área (T13) (grifos nossos).

Como observamos nos excertos acima, alguns apontamos podem ser elaborados sobre os processos de ensino e aprendizagem do conceito de área e perímetro na Educação Básica, tais como: (a) o erro pode estar associado ao mau entendimento do conceito em situaçõesproblemas; (b) projetos em que há atuação dos alunos pode potencializar a produção do 
conhecimento matemático; (c) o foco docente está em tarefas de medição; e (d) as investigações em história da matemática podem suscitar processos pedagógicos para o trabalho docente. Além desses, outros podem ser discutidos:

Permitiu verificar que os alunos continuam tendo grande dificuldade em distinguir área de perímetro, enquanto grandeza autônoma. Além de, manter a concepção numérica dissociada da concepção geométrica, ou seja, considerando apenas os elementos pertinentes ao cálculo (T16).

Em nossas análises, encontramos uma diferença no desempenho dos alunos quando mudamos a variável didática (alteramos a posição da figura), no entanto, para nossa surpresa, em alguns momentos os índices eram mais positivos nas figuras não prototípicas (T17).

A análise dos resultados revelou que: nem todos os alunos perceberam que figuras diferentes, formadas com a mesma quantidade de triângulos, têm áreas iguais; alguns dos alunos não utilizam a régua de forma adequada, no processo de medição; poucos alunos utilizaram a unidade de medida ao representar o perímetro de forma adequada; representação inadequada dos números racionais (T18) (grifos nossos).

Associados às outras inferências, podemos levantar: (a) os alunos possuem dificuldades de dissociar os conceitos área e perímetro; (b) a mudança de posição de figuras pode problematizar o contexto de aprendizagem; e (c) alguns conceitos - medição, unidade de medida, números racionais, etc - podem interferir nos processos pedagógicos de área e perímetro.

\section{Considerações finais}

Neste estudo, a intenção consistiu em produzir um estado do conhecimento no campo da Educação Matemática, visando, mais especificamente, analisar as práticas de pesquisa com alunos referente à área e perímetro na Educação Básica, quanto aos seus objetivos, metodologias de ensino e de pesquisa e suas inferências. Para tanto, analisamos três bases de dados: (a) Biblioteca Digital brasileira de Teses e Dissertações (BDTD); (2) Catálogo de Teses e Dissertações da Capes (CTD) e últimos dez anos do Encontro Nacional de Educação Matemática - ENEM. 
Perante essa investigação, evidenciamos que os estudos estão concentrados na região Sudeste do país; em sua maioria, são dissertações; e que não há elementos para suscitar um crescimento ou decrescimento das pesquisas nos últimos anos.

Elencamos, ainda, a forte ênfase nas compreensões e manifestações dos alunos quanto aos conceitos de área e perímetro, bem como o foco em tarefas e atividades na configuração de metodologias de ensino e de pesquisa. Além disso, apontamos que muitos avanços são descritos de forma genérica, o que inviabiliza nossas considerações e produções na temática.

Por fim, acreditamos que este mapeamento poderá contribuir para pesquisadores e docentes que ensejam adentrar na temática área e perímetro na Educação Básica. Esperamos, assim, que diferentes formas de pensar tais conceitos possam vir à tona em pesquisas futuras.

\section{Referências}

ALMOUlOUD, S. A.; COUTINHO, C. D. Q. E. S. Engenharia Didática: características e seus usos em trabalhos apresentados no GT-19/ANPEd. REVEMAT: Revista Eletrônica de Educação Matemática, Florianópolis, SC, v. 3, p. 62-77, 2008.

BEZERRA, L. S. O tangram e suas contribuições para o processo de abstração e compreensão dos conceitos geométricos de área e perímetro. In: XII Encontro Nacional de Educação Matemática, 2016.

BORBA, B. T. Práticas de ensino e aprendizagem de matemática e tecnologia: Um olhar para as especificidades da Educação de Jovens e Adultos (EJA). Dissertação (Ensino de Ciências e Matemática), Universidade Federal de Uberlândia, 2017.

CANNE, D. V. Uma análise praxeológica das tarefas referentes à abordagem de área e perímetro nos anos finais do Ensino Fundamental. Dissertação (Mestrado em Ensino de Ciências e Matemática) - Universidade Cruzeiro do Sul, São Paulo, 2015.

FERNANDES, F. A., MORAES, J. C. P; PEREIRA, A. L. Adolescentes em conflito com a lei nas pesquisas em Educação: um olhar a partir de dissertações e teses. Revista Educar Mais, 4(3), 773-793, 2020.

FERREIRA, L. F. D. Um estudo sobre a transição do $5^{\circ}$ ano para $06^{\circ}$ ano do ensino fundamental: o caso da aprendizagem e do ensino de área e perímetro. Tese (Doutorado em Educação Matemática e Tecnológica). UFPE-PE, Recife, 2018. 
HENRIQUES, M. D. Um estudo sobre a produção de significados de estudantes do ensino fundamental para área e perímetro. Dissertação (Mestrado Profissional em Educação Matemática) - Universidade Federal de Juiz de Fora, Juiz de Fora, 2011.

LASMAR, E. F. T. Uma experiência pedagógica de uso de tecnologias no ensino de área e perímetro com estudantes da educação de jovens e adultos (EJA). Dissertação (Mestrado em Mestrado Profissional em Educação) - Universidade Federal de Lavras, 2016.

LÜDKE, M; ANDRÉ, M. Pesquisa em educação: abordagens qualitativas. São Paulo: EPU, 1986.

NUNES, J. M. V. A prática da argumentação como método de ensino: O caso dos conceitos de área e perímetro de figuras planas. Tese (Doutorado em Educação Matemática), Pontifícia Universidade Católica de São Paulo, São Paulo, 2011.

OLIVEIRA, S. As inovações tecnológicas na educação matemática e suas concepções. Revista de Ensino de Ciências e Matemática, v. 11, n. 3, p. 126-140, 5 maio 2020.

PAULO, G. P. Uma proposta para o ensino e aprendizagem dos conceitos de área de círculo e perímetro de circunferência. Dissertação (Mestrado em Educação) - Pontifícia Universidade Católica de São Paulo, São Paulo, 2012.

PERETTI, L; COSTA, G. M. T. Sequência Didática na Matemática. Instituto de Desenvolvimento Educacional do Alto Uruguai - IDEAU- Revista de Educação Ideau. Vol. 8, n 17, Jan. /Jun., 2013.

PESSOA, G. Efeitos de uma sequência de atividades para a dissociação entre área e perímetro no $3^{\circ}$ ciclo do Ensino Fundamental. In: X Encontro Nacional de Educação Matemática, 2010 .

PIOVEZAN, A. C. T. Entre perímetros, áreas e equações: a conscientização das ações de ensino. In: XI Encontro Nacional de Educação Matemática, 2013.

PRATES, U. As elaborações de estudantes do sexto ano do ensino fundamental sobre o conceito de área a partir de atividades orientadoras de ensino. In: X Encontro Nacional de Educação Matemática, 2010.

QUEVEDO, G. A. Compreensão dos conceitos de área e perímetro: um estudo de caso. Dissertação (Mestrado Profissionalizante em Ensino de Matemática), Universidade Federal do Rio Grande do Sul, Rio Grande do Sul, 2016.

ROMANOWSKI, J. P.; ENS, R. T. As pesquisas denominadas do tipo "estado da arte" em educação. Diálogo Educ., Curitiba, v. 6, n.19, p.37-50, set./dez. 2006. 
ROSA, R. X. Projeto de Modelagem Matemática e Teoremas em Ação: Uma Investigação sobre os Conceitos de Área e Perímetro. Dissertação (Mestrado em Ensino de Ciências). Universidade Estadual de Maringá, Paraná, 2017.

SANTOS, E. S. C. Comparando área de figuras por visualização e sobreposição. In: XI Encontro Nacional de Educação Matemática, 2013.

SANTOS, D. C. S. Aprendizagem dos conceitos de perímetro e área enquanto grandezas na educação de jovens e adultos (EJA): o contexto desflorestamento da Amazônia. In: X Encontro Nacional de Educação Matemática, 2010.

SANTOS, E. R. A influência das variáveis didáticas na resolução de problemas com área e perímetro. In: X Encontro Nacional de Educação Matemática, 2010.

SENZAKI, N. N. Conceitos de área e de perímetro: um estudo metanalítico. Tese (Doutorado em Educação Matemática), Pontifícia Universidade Católica de São Paulo, São Paulo, 2019.

TRIPP, David. Pesquisa-ação: uma introdução metodológica. Educação \& Pesquisa, São Paulo, v. 31, n. 3, p. 443-466, set./dez. 2005.

ZILS, M. I. E. Uma análise das abordagens desenvolvidas em livros didáticos sobre os conteúdos escolares "área" e "perímetro". Dissertação (Mestrado em Educação Científica), Universidade Tecnológica Federal do Paraná, Ponta Grossa, 2018.

\section{HISTÓRICO}

Submetido: 01 de março de 2021.

Aprovado: 19 de abril de 2021.

Publicado: 14 de julho de 2021. 